\title{
Aiming to better serve our rural populations
}

\author{
Peter D. Metcalfe, MD \\ Department of Surgery, Division of Pediatric Surgery, University of Alberta, Edmonton, AB, Canada
}

Cite as: Can Urol Assoc J 2019;13(12):395. http://dx.doi.org/10.5489/cuaj.6316

See related article on page 391

$\mathrm{T}$ his month's CUAJ article, "Evaluating the distance travelled for urological pediatric appointments," highlights one of the difficulties of subspecialty practice in Canada. A limited number of pediatric urologists must serve the entire geographic breadth of the country, and this creates challenges. Our 2011 paper noted the significant costs and burden to the travelling family; we have been using telehealth to minimize some of this burden. Although never perfect, I find it very effective for obviously non-surgical conditions (e.g., incontinence, urinary tract infection, antenatal hydronephrosis). We estimated a median savings of \$500-700 per patient. ${ }^{1}$

The authors of this current study discuss other solutions, including combining appointments with other specialists while in the city and improving primary care education. ${ }^{2}$ However, they also mention having the urologist travel to the underserved area. In Alberta, a urologist travels to Yellowknife $(1400 \mathrm{~km})$ on a regular basis for a general clinic. Many patients still have to travel long distances to Yellowknife, but their burden is lessened. Several other urologists also travel 1-2 hours to peripheral community hospitals. This is very common among pediatric urologists in the U.S., who often travel for clinic and perform minor surgeries in peripheral sites.

The idea of a travelling pediatric urologist is commendable — both for patient benefit and to potentially reduce the

strain on tertiary hospital clinics, as this could lessen patient visits and reduce local waiting lists. If a case for clinical need can be developed, it should certainly be welcomed by underserved communities. Obvious limitations would be to ensure enough patients are available and to determine whether a bi-annual clinic would be adequate for more urgent cases. Furthermore, this endeavor would obviously require significant support from the provincial health authority (stipend, travel costs, etc.) and urology colleagues (call coverage, sharing local resources).

The next obvious progression would be the potential to perform surgery at these outside sites, although this would present a much more significant logistical and safety issue.

We look forward to hearing how the authors proceed and if they are successful in delivering better care to their rural populations.

Competing interests: The author reports no competing personal or financial interests related to this work.

\section{References}

1. Shivii S, Metcalfe P, Khan A, et al. Pediatric surgery telehealth: Patient and clinician satisfaction. Pediatr Surg Int 2011;7:523-6.

2. Otis-Chapados $S$, Coderre $K$, Bolduc $S$, et al. Evaluating the distance travelled for urological pediatric appointments. Can Urol Assoc J 2019;13:391-4. http://dx.doi.org/10.5489/cuai.5892

Correspondence: Dr. Peter D. Metcalfe, Department of Surgery, Division of Pediatric Surgery, University of Alberta, Edmonton, AB, Canada; pmetcalf@ualberta.ca 